\title{
Fragmentos da memória: cultura e língua portuguesa em Maputo, homenagem aos irmãos moçambicanos
}

\author{
Pieces of memory: Portuguese culture and language in \\ Maputo, homage to mozambiquean brothers
}

\author{
Nilce da SILVA \\ Aparecida do Carmo Frigeri BERCHIOR
}

\begin{abstract}
RESUMO
Este artigo revela a importância de não deixar esquecida e desconhecida lembranças do aprendizado da Língua Portuguesa de um grupo de moçambicanos, habitantes da cidade de Maputo, que não teve esta língua como língua materna, no sentido da reflexão acerca da relação entre língua e construção da cidadania. Pelo viés da coleta de dado de registro oral e a partir do tratamento dado ao material, obtivemos resultados que nos mostraram a diversidade étnico-cultural na capital moçambicana. Além disto, o conjunto das entrevistas realizadas indicou também que as relações familiares e as relações estabelecidas na instituição escolar são marcantes para a inserção destes sujeitos no mundo lusófono, após a Independência do país de Portugal. Ainda, o artigo pretende se constituir em subsídio para a implementação da Lei 11.645/08 acerca do estudo da temática História e Cultura AfroBrasileira em salas de aula.
\end{abstract}

Palavras-chave: aprendizado da Língua Portuguesa, Lei 11.645/08, resgate das memórias, Maputo.

\begin{abstract}
This article discloses the importance of keeping alive and recognized the memories about the learning of Portuguese Language by a Mozambiquean group, citizens of Maputo, whose did not have this language as maternal language, in the direction of the reflection concerning the relation between language and citizenship's construction. From data collection of verbal register and from the treatment given to them, we got results that show the ethnic-cultural diversity inside Mozambique's capital. Moreover, the set of the interviews also indicated that the familiar relations and the relations established inside school institution are strong for the insertion of these citizens in the Lusophone world, after Mozambique's Independence
\end{abstract}


from Portugal. Still, the article intends to consist in subsidy for the implementation of Law 11.645/08 concerning the study of Afro-Brazilian Culture and History inside classrooms.

Index Terms: Law 11.645/08, learning of Portuguese Language, Maputo, memories rescue.

\section{RÉSUMÉ}

Cet article révèle l'importance de ne pas laisser oublié et ne pas perdre connaissance des souvenirs de l'apprentissage de la Langue Portugaise d'un groupe de Mozambicains, habitants de la ville de Maputo, qui n'a pas eu cette langue comme langue maternelle, dans le sens de la réflexion concernant la relation entre langue et construction de la citoyenneté. A partir de données et de registre verbal du terrain et aussi à partir du traitement de ces données, nous avons obtenu des résultats qui montrent la diversité éthique culturelle dans la capitale mozambicain. En outre, l'ensemble des interviews réalisées, a démontré qu'après l'Indépendance du pays de Portugal, les relations familières et les relations établies dans l'institution scolaire sont marquantes pour l'insertion de ces sujets dans le monde lusophone. Encore, l'article vise à se constituer comme subvention pour la mise en oeuvre de la Loi 11.645/08 concernant l'étude de la thématique Histoire et de la Culture Afro-Brésiliénne et Africaine dans les classes.

Mots clés: l'apprentissage de la Langue Portugaise, Loi 11.645/08, Maputo, souvenirs de l'apprentissage.

\section{Introdução}

Este artigo tem como principal objetivo tirar do silêncio lembranças de um grupo de moçambicanos, habitantes da cidade de Maputo, e fazer da Revista Acolhendo a Alfabetização de Países em Língua Portuguesa suporte para a apresentação de registros escritos, que materializem as práticas e representações destes sujeitos, no âmbito do aprendizado da Língua Portuguesa. Tal proposta pretende integrar a elaboração de um corpus prático-teórico com a finalidade de compor parâmetros curriculares de abordagem étnicoraciais, favorecendo a adequação desta temática na educação básica, uma vez que se pretende constituir como subsídio para a Lei 11.645/08, que es- 
tabelece como obrigatório o estudo da História e Cultura Afro-Brasileira e Africana, e também Indígena, em salas de aula. Tal legislação, como sabemos, vem exigindo modalidades de atualização continuada para educadores, tanto para repertório informativo específico como para formação de excelência na matéria. Desta forma, este artigo, assim como os números cinco e seis deste periódico, pretende, por meio do suporte escrito e eletrônico, registrar experiências de vida para a reconstituição, ainda que parcial, da memória social do povo moçambicano. Acreditamos que conhecer e relatar as lembranças que a vida em família, na escola, no ambiente de trabalho, dentre outros locais produziram nas histórias de inúmeros seres humanos — que desde tenra idade são colocados sob a influência destas instâncias sociais é um desafio para todo pesquisador interessado na gênese dos processos de formação identitária relacionada, sobremaneira, ao uso da língua.

O material, que agora apresentamos, é fruto de curta missão de trabalho na cidade de Maputo, ele nos propicia reflexões sobre o posicionamento do pesquisador frente ao seu objeto, quando há a necessidade de uma pesquisa de campo. Para Desaulniers (1997), é o ponto de vista do pesquisador que cria um objeto de estudo e não o contrário. Reflexão que, para nossa proposta, diante da escolha de uma metodologia de pesquisa com suporte no registro oral, torna-se fundamental. Segundo o mesmo autor, abandonamos a exclusividade do uso da pesquisa quantitativa, para nos aproximar das complexas relações históricas e sócio-culturais, presentes no cenário dos relatos, uma vez que nestes estão reacendidas vivências e experiências humanas. Nesta direção, procuramos compreender dimensões e indicadores na captura da memória social do aprendizado da Língua Portuguesa, realizando um trabalho de campo que implicou em um empreendimento de pesquisa de alcance interdisciplinar. Por este viés, foi-nos possível captar dimensões relevantes, que configuram a complexidade do real, neste caso, alguns moradores da cidade de Maputo - falantes e escritores de Língua Portuguesa, que vivenciam um desenvolvimento acelerado do capitalismo, com suas 
acentuadas cisões na estrutura social, em relação à distribuição de riqueza. Deste modo, ao considerarmos o processo de urbanização, implicado nesta cidade africana, percebemos a construção de uma cidadania no sentido de formar e se autoformar, tecendo, por meio do texto escrito, parte da memória social referente ao aprendizado da Língua Portuguesa.

Em suma, procuramos, neste artigo, compartilhar com o leitor experiências silenciadas, suprimidas e/ou mesmo conhecidas apenas no âmbito doméstico dos sujeitos que compõem a pesquisa e, ainda, refletir sobre o papel desempenhado pela instituição escola e pelas relações familiares, na formação destas memórias.

\section{Um olhar sobre a cidade de Maputo}

\subsection{Memória, magia e corpo a palavra é a cidade}

[...] onde te revelas e se revela a aventura, mergulho no ilimitado [...] (Lourenço Marques, 1946

Hoje, com cerca de 17,5 milhões de habitantes, ocupando uma extensão territorial de aproximadamente $801.590 \mathrm{~km}^{2}$, Moçambique é a mais populosa das antigas colônias portuguesas de África. A agricultura é a base da economia do país. Segundo Mouzinho e Nandja (2006), mais de 70\% da população vivem em áreas rurais, dedicando-se, principalmente, à agricultura, silvicultura e pesca. Metade da população está na faixa etária de 6-24 anos e a maioria é do sexo feminino. Cerca de $80 \%$ do investimento público vão para os setores sociais (educação, saúde e provisão de água), bem como a agricultura, transportes e infra-estruturas rurais.

A capital desse país é Maputo² ${ }^{2}$ sua maior cidade, que está localizada ao sul do país, fazendo limite ao norte com o distrito de Marracuene; a no-

\footnotetext{
${ }^{1}$ Poema incluído em Negra Azul, assinado pelo heterônimo Duarte Galvão. Disponível em: <http://www.lu sitanistasail.net/secco01.htm>. Acesso em: 21 maio 2008.
} 
roeste e oeste com o município da Matola e Boane e ao sul com o distrito de Matutuíne. Chamava-se Lourenço Marques e passou a Maputo, depois da Independência deste país de Portugal em 1975.

Por sua posição estratégica na Costa Oriental da África, Moçambique tem sido, ao longo dos tempos, ocupada por muitos povos, apresentando um enorme mosaico de indivíduos de diferentes origens e culturas, africanos (negros e mestiços), árabes, indianos, europeus, etc.

Dos povos africanos, destacamos como povoadores de quase toda a África ao sul do deserto do Saara, os grupos étnicos-lingüísticos descendentes dos Bantu. Assim, em Maputo, encontramos Suahili, Macua-Lomué, Maconde, Ajaua (apesar de serem tipicamente habitantes ao norte do país, assim como, os Nhanjas e os Angoni). Já no sul do país, destacam-se os Tonga (divididos em Changana, Chope, Tsua e Ronga), agricultores e pastores do sul de Moçambique, presentes fortemente hoje na cidade de Maputo.

No céu da cidade, vemos tanto torres de catedrais como minaretes. E, ao caminharmos junto ao povo desta cidade, percebemos, assim, a presença de católicos e muçulmanos. Nesta direção, não menos importantes são os templos evangélicos edificados em inúmeras ruas da cidade e ainda percebemos na população características do Hinduísmo, membros de comunidades que, na sua maioria, oriundos do Estado de Gujarat, local em que se situavam os enclaves de Goa, Damão e Diu, constituintes também do antigo Estado Português da Índia. Finalmente, lembramos dos anúncios lidos, nos mais diferentes jornais moçambicanos, em que a figura dos feiticeiros e das religiões africanas mostram-se fortemente presentes.

De acordo com dados do governo moçambicano, a diversificada população de Maputo tem, aproximadamente, 1.000.000 habitantes, distribuídos em sua área de $300 \mathrm{~km}^{2}$.

\footnotetext{
${ }^{2}$ A cidade de Maputo não deve ser confundida com a Província de Maputo, que ocupa o território mais meridional de Moçambique.
} 
A cidade é composta por grandes avenidas cujos nomes fazem alusão a líderes socialistas soviéticos - Marx, Lênin, dentre outros; líderes africanos - Lumumba, por exemplo; e heróis da Independência Moçambicana - Mondlane, Samora Machel e outros.

Maputo possui importantes monumentos ${ }^{3}$, como fortalezas, praças e estátuas, que nos elucidam a luta do povo moçambicano para se libertar do colonizador. Destacam-se: a Fortaleza de Maputo; o Museu Nacional da Moeda; a Biblioteca Nacional (ainda que em reforma em março deste ano), a Casa de Ferro, as estátuas de Eduardo Mondlane e de Samora Machel, dentre outras.

Diante da multiplicidade acima, em síntese, explanada, para nossa proposta torna-se essencial retomar alguns aspectos sobre língua, memória e identidade, a fim de contribuir com reflexões sobre os dados por nós coletados, em pesquisa de campo.

\section{Língua, Memória e identidade: considerações teórico-metodológicas}

A memória é a mais épica de todas as faculdades.

(Walter Benjamin)

As complexas relações que se estabelecem entre a identidade cultural moçambicana têm como princípio uma sociedade formada por diferentes etnias, o que implica, ainda que parcialmente, diferentes usos, costumes e línguas. Ao lado desta característica, historicamente, tal sociedade teve como demanda cultural a adoção da Língua Portuguesa como oficial prevista na Constituição da República, de 16 de novembro de $2004^{4}$, já que esta opção indica a necessidade unificadora da expressão do país, considerando-se os múltiplos contextos presentes no sentimento da moçambicanidade.

\footnotetext{
${ }^{3}$ Não deixe de ver o álbum fotográfico da cidade publicado neste volume.

4 “Artigo 10: Língua oficial. Na República de Moçambique a Língua Portuguesa é a língua oficial” (p. 3, disponível em: <http://www.mozambique.mz/pdf/constituicao.pdf>. Acesso em 24 maio 2008).
} 
Justamente neste ponto, fez-se mister retomar a definição de Stephen Ullmann, fundamentando-se em Ferdinand Sausseare, de que "a língua é a súmula total dos sistemas lingüísticos que os membros individuais da comunidade têm na memória" (1977, p. 45). Neste aspecto, as tensões que se estabelecem entre uma língua oficial e uma língua materna propiciam-nos repensar a identidade unificadora, que assume a Língua Portuguesa oficial, de origem latina e, portanto, diversa da origem das línguas das diferentes etnias, que compõem a identidade nacional moçambicana.

Assim, neste contexto, procuramos superar o desafio, da escolha metodológica ideal para uma pesquisa de campo, frente à realidade que nos era apresentada. No curto período de tempo disponível, precisávamos averiguar, ainda que de modo introdutório e exploratório, as relações sócio-culturais, em Maputo, diante de uma população inserida no plurilinguismo sóciocultural: línguas nativas (anteriores ao processo de colonização portuguesa), línguas estrangeiras (ocidentais e orientais) e, ainda, a Língua Portuguesa. Dito de outro modo: como salvar do esquecimento experiências sociais relevantes, que poderiam nos indicar o caminho da reflexão acerca dos lugares ocupados pelas diferentes línguas correntes em Maputo, para os sujeitos que fazem a história deste país, há tão pouco tempo independente? Ou seja, como resgatar as memórias da inserção no mundo lusófono após a Independência do país?

De acordo com Pollak (1992), a memória é, em parte, herdada e não se refere apenas à vida física da pessoa. Essa sofre flutuações por ser afetada pelo momento em que se expressa. Ou seja, são as preocupações do momento, a condição real em que o sujeito se encontra que estrutura a memória desdobrada, e aquele que ouve, terá acesso a esse desdobramento. E ainda, para o autor "a memória é um fenômeno construído" (1992, p. 210) e como tal apresenta três elementos essenciais guiados pelo eixo de que se reconstitui a memória tanto para si como para os outros: 1) A memória está imersa em uma unidade física, ou seja, o sentimento de ter fronteiras físicas, no 
caso do corpo da pessoa, ou fronteiras de pertencimento ao grupo, no caso de um coletivo. 2) A memória é inserida na linha do tempo; no sentido físico da palavra e, também, no sentido moral e psicológico. 3) A memória, ao ser explicitada, pede o sentimento de coerência, ou seja, de que os diferentes elementos que formam um indivíduo, sejam efetivamente unificados.

Para Pollak (1992), estes três elementos são fundamentais — pois fornecem o sentimento de unidade para a pessoa - de modo que, se houver forte ruptura em um deles — o que implica na quebra dos demais - observam-se fenômenos patológicos.

Sendo assim, no contexto da realização desta pesquisa, entendemos a memória como um elemento constituinte do sentimento de identidade, tanto individual como coletiva, já que ela é fator indispensável na unidade do ser, na reconstrução de si e de seu grupo. Ao assimilarmos a identidade social à imagem de si, para si e para os outros, há um elemento dessas definições que, necessariamente, escapa ao indivíduo e, por extensão, ao grupo: este elemento, obviamente, é o Outro. Ninguém pode construir uma autoimagem isenta de mudança, de negociação, de transformação, em função dos outros. A construção da identidade é um fenômeno que se produz em referência aos outros, em referência aos critérios de aceitabilidade, de admissibilidade, de credibilidade, e que se faz por meio da negociação direta com outros. Vale dizer que memória e identidade podem, perfeitamente, ser negociadas, e não são fenômenos que a serem compreendidos como essências de uma pessoa ou de um grupo (POLLAK, 1992, p. 211).

As memórias fazem evocar uma parte significativa da infância, que estabeleceu contato com as diferentes instâncias do mundo social. Por meio do resgate da memória, buscamos o enigma que é a formação do ser humano, desde a infância, inserido em uma sociedade previamente definida.

Diante destas opções e considerações teóricas, optamos pela abordagem qualitativa da pesquisa, sendo que tivemos contato estreito com 42 dos sujeitos investigados e, apenas, com três deles, procedemos à aplicação de 
um questionário, contendo o mesmo teor da entrevista. Por meio do resgate destas memórias, recuperamos as lembranças relacionadas ao aprendizado da Língua Portuguesa. Buscamos, assim, conhecer as relações entre este aprendizado e a formação das memórias em si, diante das complexas relações e das riquezas culturais deste povo, especificamente, na tentativa de reconstruir e dar-se a conhecer uma identidade que se oraliza, que se mostra pelo ato de contar. Para tanto, consideramos, que ao falar e se utilizar da fala, cada sujeito, o senhor da sua fala, com controle sobre ela, por seu caráter individual. Entretanto, enquanto pesquisadores, durante a realização deste trabalho de campo, nós estivemos atentos ao fato de que a comunicação estabelecida entre pesquisador e sujeito se efetivou na língua oficial — institucionalizada.

Desta forma, consideramos o seguinte: ao relatar em Língua Portuguesa, os sujeitos deste trabalho efetivaram uma narração oral, isto é, contaram-nos uma história rememorada, reminiscência carregada de entonações psicológicas, que foram substancialmente prejudicadas, por não conter elementos da tradição. Para Walter Benjamin, "a reminiscência funda a cadeia da tradição, que transmite os acontecimentos de geração em geração" e nela está incluída "todas as variedades da forma épica", em que se encontra "em primeiro lugar a encarnada pelo narrador", pois a reminiscência "tece a rede que em última instância todas as histórias constituem entre si”, em que "uma se articula na outra" (BENJAMIN, 1993, p. 211). Assim, cada narrador sujeito da pesquisa "vive uma Scherazade, que imagina uma história em cada passagem da história que está contando” (BENJAMIN, 1993, p. 211).

Diante da complexidade, relatamos os procedimentos adotados para a metodologia, tendo como fundamentação as questões apontadas neste tópico do artigo. 


\title{
3 Procedimentos metodológicos
}

\author{
[...] Eu tambor \\ Eu suruma \\ Eu negro suaíli \\ Eu Tchaca \\ Eu Mahazul e Dingana \\ Eu Zichacha na confidência dos ossinhos mágicos do Tintholo \\ Eu insubordinada árvore da Munhuana \\ Eu tocador de presságios nas teclas das timbila chopes \\ Eu caçador de leopardos traiçoeiros \\ Eu xiguilo no batuque.[...] \\ (Craveirinha, Manifesto)
}

Neste conjunto de policulturas, que vivenciamos em missão de trabalho, em Moçambique, no mês de março de 2008, com o apoio do CNPq, um dos aspectos a ser analisado, que acreditamos ser essencial, refere-se, como visto acima, ao registro oral. Utilizando-se de roteiro de entrevista semiestruturado, intentamos permitir aos sujeitos construir, espontaneamente, a narração de sua história, tendo como parâmetro inicial o contato destes com o mundo lusófono. Ou seja, optamos pelo método de pesquisa denominado "história oral" para referendar as fontes primárias da investigação. Tal metodologia a partir da metade do século XX firmou sua confiabilidade, principalmente, favorecida pelo advento de mídias, como o gravador. Por estes novos recursos, esta metodologia passou a contar com o registro documental, ampliando, assim, os olhares sobre o mesmo acontecimento, contando, para tanto, com o sujeito agente, com as suas narrativas orais individuais, percebido em um tempo/espaço sócio-histórico. Esta abordagem permitiunos nova luz sobre a compreensão desta sociedade, pois "a evidência oral, transformando os 'objetos' de estudo em 'sujeitos', contribui para uma história que não só é mais rica, mais viva e mais comovente, mas também mais verdadeira" (THOMPSON, 1992, p. 137).

Nosso recorte na coleta de dados limitou-se a sujeitos moradores da cidade de Maputo, com os quais tínhamos relativo contato cotidiano. Ainda pareceu-nos essencial que os sujeitos-objeto da pesquisa se encontrassem em ambientes comuns ao cotidiano da capital, caracterizando, dentro do 
possível, o mínimo de formalidade. Esses parâmetros objetivaram considerar, dentro da proposta inicial, também as trajetórias pessoais e, com estas, reacender a memória, tendo como motivo o primeiro contato com a língua oficial, nas modalidades oral e escrita. Paralelamente, buscávamos encontrar subsídios para as relações que se estabeleceriam entre língua oficial e língua materna, uma vez que na Constituição do país (2004, p. 3) as várias línguas, que compõem a paisagem cultural de Moçambique, encontram-se valorizadas enquanto patrimônio cultural e educacional. Fato que nos permitiu agregar aos resultados a valorização da identidade, dentro deste contexto.

Assim, os dados foram coletados em diversos locais que compõem a paisagem urbana de Maputo: lojas, bares, supermercados, restaurantes, escolas, bibliotecas, procurando favorecer, aos nossos entrevistados, a arte de narrar. Dos depoimentos obtidos junto aos 45 sujeitos desta pesquisa, observamos as seguintes condições prévias:

1. Sujeitos escolhidos de modo aleatório, quanto à faixa etária, condição sócio-econômica, sexo e níveis de escolaridade.

2. Sujeitos efetivamente moradores de Maputo.

3. Sujeitos de nacionalidade moçambicana, oriunda do nascimento no país.

Atendidas estas condições, a coleta de dados compreendeu os seguintes passos:

a) Conversas informais acerca de assuntos triviais: vida, motivos da permanência do pesquisador no local, o nosso dia-a-dia em missão de trabalho, na zona central da capital Maputo.

b) Convite para algumas destas pessoas relatarem a forma de contato com a língua oficial do país, a Língua Portuguesa.

c) Um roteiro mínimo para a condução do registro gravado da coleta de dados, em que se distinguisse a faixa etária dos sujeitos, a identidade origem, isto é, etnia, língua materna. Também, a solicitação da idade em que 
teve contato/aprendizagem com a Língua Portuguesa, a forma como aconteceu: as memórias deste aprendizado.

d) As entrevistas eram gravadas e, algumas, anotadas para depois serem reescritas. Também, foram distribuídos, junto a alunos do curso de Pós-Graduação em Educação de Adultos na Universidade Eduardo Mondlane, 13 questionários para preenchimento e posterior devolução, com o mesmo objetivo das entrevistas.

e) Transcrição na íntegra das entrevistas.

f) Análise e tratamento dos resultados.

Ainda ressaltamos que todo o processo contou com a permissão do entrevistado.

\section{Do tratamento dos dados e resultados preliminares}

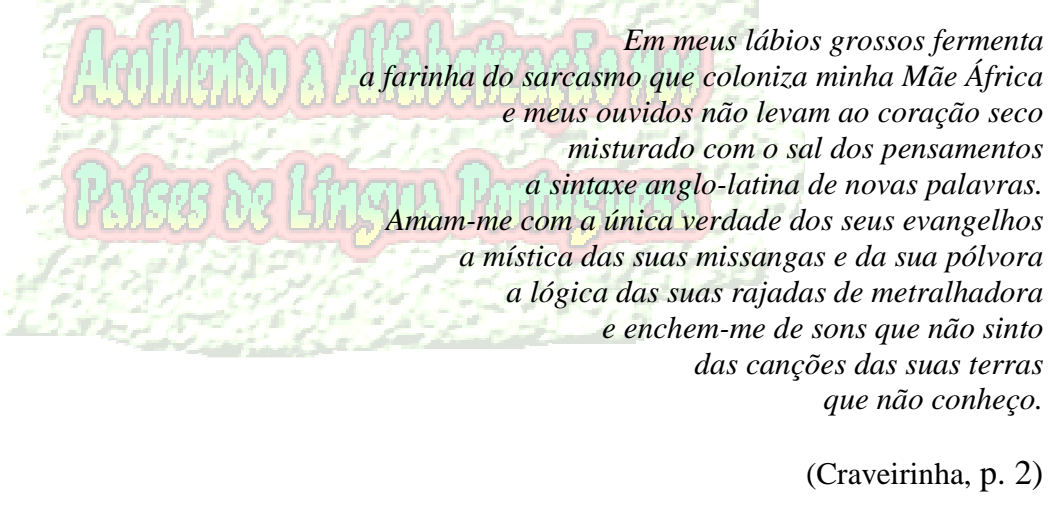

Dos 15 questionários impressos distribuídos, conforme acima, somente 3 retornaram totalmente preenchidos, sendo, portanto, uma amostra comprometida, somente servindo para corroborar os resultados da coleta oral de dados.

Os registros orais coletados para a investigação foram transcritos, seguindo os direcionamentos de Tourtier-Bonazzi (2001), proposto no texto “Arquivos: propostas metodológicas” e, após o devido tratamento do material coletado, procedemos às análises e reflexões sobre o mesmo, dando relevância a cada silêncio, cada riso ou cada ruptura do discurso, pois para 
Thompson, "a lição importante é aprender a estar atento àquilo que não está sendo dito, e a considerar o que significam os silêncios" e acrescenta: "os significados mais simples são provavelmente os mais convincentes" (THOMPSON, 1992, p. 204-5).

Os resultados dos registros, dentre os 45 nativos entrevistados, seguindo-se os aspectos aleatórios, apontam para uma faixa etária entre 16 e 50 anos, em uma população de ambos os sexos e de condição sócioeconômica variada e de diversos níveis de escolaridade e de variado grupo étnico-lingüístico, conforme demonstra o quadro abaixo:

\begin{tabular}{|c|c|c|c|c|c|c|c|}
\hline \multirow{2}{*}{$\begin{array}{c}\text { Grupo etno- } \\
\text { lingüístico }\end{array}$} & \multicolumn{3}{|c|}{ Homens } & \multicolumn{3}{c|}{ Mulheres } \\
\cline { 2 - 7 } & $\begin{array}{c}\text { Até 25 } \\
\text { anos }\end{array}$ & $\begin{array}{c}\text { Até 45 } \\
\text { anos }\end{array}$ & $\begin{array}{c}+45 \\
\text { anos }\end{array}$ & $\begin{array}{c}\text { Até 25 } \\
\text { anos }\end{array}$ & $\begin{array}{c}\text { Até 45 } \\
\text { anos }\end{array}$ & $\begin{array}{c}+45 \\
\text { anos }\end{array}$ & Total \\
\hline Changana & 2 & 3 & 2 & 6 & & & 13 \\
\hline Chope & & 3 & 1 & 1 & 1 & & 6 \\
\hline Tsua & & 2 & & & & 1 & 3 \\
\hline Ronga & & 4 & 3 & 3 & 1 & 2 & 13 \\
\hline Maconde & & 1 & 1 & & & & 2 \\
\hline Outros & 3 & 1 & 1 & & 2 & 1 & 8 \\
\hline Total & $\mathbf{5}$ & $\mathbf{1 4}$ & $\mathbf{8}$ & $\mathbf{1 0}$ & $\mathbf{4}$ & $\mathbf{4}$ & $\mathbf{4 5}$ \\
\hline
\end{tabular}

Conforme o quadro acima, é relevante destacar que os entrevistados pertencem a diferentes grupos étnico-lingüísticos, situação que, em termos qualitativos - não quantitativamente, nem proporcionalmente - reflete a realidade da população de Maputo.

Ainda os resultados apontam que, dentre estes sujeitos nativos e habitantes do espaço urbano de Maputo, nenhum deles teve a Língua Portuguesa como língua materna e que aprenderam esta língua oficial, na modalidade escrita, majoritariamente, na instituição escolar. Já na modalidade oral, o contato inicial deu-se em casa (em torno de 70\%). Entretanto, a aquisição do domínio da leitura e da escrita ocorreu na escola (em torno de 90\%).

Também ressaltamos que, das 45 entrevistas e questionários realizados, para fins deste artigo, apenas $25 \%$ das pessoas declararam ter experiências significativas com o aprendizado da Língua Portuguesa. Os demais, $75 \%$, disseram que "no momento não tinham nada para dizer" ou "que não 
se lembravam de nada interessante" ou ainda "que precisariam pensar mais um pouco".

Sendo assim, do nosso universo de pesquisa (45 entrevistados), para fins desta reflexão, contamos apenas com depoimentos de 11 deles, já que os demais, 34 pessoas, afirmaram não terem nada a dizer acerca do aprendizado da Língua Portuguesa.

Sendo assim, nesta amostra composta por 11 pessoas, destacamos que todas guardam lembranças acerca do aprendizado da Língua Portuguesa relativas: à sua própria vida, à vida de seus familiares próximos (mãe, filhos, avós) e aos momentos vivenciados na instituição escolar.

Por exemplo, um jovem de 25 anos, estudante de décima primeira classe, que se autodenominou da etnia Bantu, disse-nos ter ficado emocionado ao aprender o abecedário e quando viu o filho falando Língua Portuguesa.

Do mesmo modo, outro de nossos entrevistados, homem, 26 anos, estudante do décimo segundo ano, cuja língua materna foi o Changana, declarou-nos: Eu aprendi a escrever em Português em Maputo, com sete ou oito anos. Me emociono ao lembrar quando aprendi o abecedário. Ah... também quando ganhei o título de melhor poeta da escola no ensino secundário, é inesquecível.

Nesta direção, destacamos passagem da entrevista concedida por uma mulher, 25 anos, bacharel em Turismo, cuja língua materna foi o Changana: Eu me emociono quando lembro do texto literário que fiz transformado em teatro quando estava na décima classe e de uma professora de Português, que incentivava a leitura de quatro livros, que eram de leitura obrigatória. Destes tinha que fazer um resumo, ficha de literatura, uma conversa, peça teatral e poesia. Ela ainda acrescenta tive grande emoção quando consegui ler a Bíblia e quando ensinei meu irmão mais novo por meio de ditados, ocasiões divertidas. 
Com relação às memórias do aprendizado da Língua Portuguesa relacionado aos parentes próximos, destacamos o depoimento de uma mulher, 32 anos, que estudou até o décimo segundo ano: Fico emocionada [quando me lembro] de quando dominei perfeitamente a leitura da língua e também quando ouvi meu filho começar a falar nesta língua. E ainda, destacamos a narração de uma jovem mulher, 19 anos, estudante de décima primeira classe, cujos familiares tem como língua materna o Bitonga e que aprendeu a falar o Português com um ano, em casa, e a escrever, com cinco anos, em casa também: eu me emociono quando lembro dos momentos quando ensinava a minha avó a falar e a escrever em Português... Era lindo, emocionante.

Além destes, para este artigo, transcrevemos o depoimento emocionado que um homem de 38 anos, cuja língua materna é o Ronga, com grau universitário, a respeito de quando conseguiu falar na Língua Portuguesa em Matola, grande Maputo: Até os dez anos, eu tinha um conhecimento da Língua Portuguesa muito pobre e muitos conhecidos riam de mim. Isto me fazia muito mal e fazia com que eu evitasse falar.

Outra estudante, que tem como língua materna o Sena/Shona [sic], também com nível universitário, aprendeu a falar, ler e escrever a Língua Portuguesa com dez anos de idade na escola, em Maputo. Apesar disto, contou-nos sobre o momento inesquecível — de grande sofrimento - que vivenciou quando prestou exame para ingressar no ensino superior: Foi um grande sofrimento fazer este exame para ingressar no curso superior aqui em Maputo. Eu tinha aprendido a língua quando era criança, mas deixei de praticar porque fui morar no Zimbabwe e lá se fala Inglês.

Com outra conotação, escutamos o depoimento de uma jovem, com 24 anos, garçonete, falante nativa de Ronga. Ah, eu me lembro de quando escutei filho da puta na escola. Cheguei em casa e chamei minha mãe de puta. Mas ela não sabia o que era e eu também não. Aí minha tia veio e explicou (risos). 
Finalmente, acrescentamos que nossos registros propiciaram a contextualização de aspectos sócio-culturais e evidenciaram a confluência nas narrativas - da memória viva dos povos-irmãos moçambicanos, que levam à assertiva que ressignifica a identidade da nação, pois "recordar a própria vida é fundamental para nosso sentimento de identidade" (THOMPSON, 1992, p. 208). E, neste sentido, "uma das mais profundas lições da história oral é a singularidade, tanto quanto a representatividade, de cada história de vida" (THOMPSON, 1992, p. 174).

\section{Considerações finais}

$$
\begin{array}{r}
\text { Ser ilha, sem limites } \\
\text { vertigem, vibração } \\
\text { vôo da memória } \\
\text { na subversão de si } \\
\text { mesma, (...) }
\end{array}
$$

(Virgílio de Lemos $^{5}$ )

Ter recorrido à metodologia de pesquisa de coleta de dados, por meio de registros orais, propiciou-nos conhecer, ainda que não em profundidade, percursos individuais e compartilhar as experiências significativas de alguns representantes dos povos moçambicanos, no processo de aprendizagem da Língua Portuguesa.

Pareceu-nos decisivo a relação, em uma primeira infância, com a Língua Portuguesa oral, falada como segunda língua, dentro das etnias, cuja língua materna compõe-se de uma imensa diversidade: Changana, Chope, Tsua, Ronga, Maconde, dentre outras.

Como já dissemos, nenhum dos entrevistados teve como língua materna, a Língua Portuguesa. Esta, por ser a oficial e carregar a estatura de "língua padrão unificadora", distancia-se da comunicação espontânea da sociedade; aspecto que vem corroborado pelo fato de somente um dos en-

\footnotetext{
${ }^{5}$ Disponível em: < http://www.lusitanistasail.net/secco01.htm>.
} 
trevistados ter aprendido a modalidade escrita da língua portuguesa em casa e, portanto, fora de um ambiente institucionalizado. Para todos os demais, a Língua Portuguesa, na modalidade escrita, tem seu processo de aprendizagem iniciado na instituição escola, portanto em ambiente formal. Temos condições de inferir, também, na mesma direção, que o fato de não se expressarem na sua língua materna, fez com que 34, dos 45 sujeitos entrevistados afirmassem não ter nada de importante a contar acerca do aprendizado da língua do antigo colonizador.

Foi-nos possível constatar, ainda, o papel efetivo da escola no aprendizado formal da Língua Portuguesa escrita, na medida em que esta instituição produz, nas histórias de vida dos moradores de Maputo, memórias que atravessam o tempo e acompanham o sujeito.

Na realidade da capital do país, observamos que boa parte dos sujeitos entrevistados aprendeu a falar Português em suas casas ${ }^{6}$ e, ainda, o uso corrente desta língua, no ambiente de trabalho, mostrou-se como um elemento que faz desta língua oficial um importante instrumento de inserção econômica e social.

Além destas considerações do ponto de vista da recente história do país, constatamos que os sujeitos mais jovens desta pesquisa ouviram a modalidade oral da língua oficial em casa, dominando-a, oralmente, antes dos sete anos, mas como segunda língua e não como língua materna. Já as pessoas acima de 40 anos - que viveram, portanto, sob o regime colonial, vieram a aprender o Português mais tardiamente, por volta dos 10, 12 anos e na escola, isto é, de forma institucionalizada.

Consideramos, também, à luz dos dados coletados que as experiências relativas ao aprendizado da Língua Portuguesa, registradas por meio da publicação deste artigo, em que foram apresentadas e analisadas histórias de vida (imagens, recordações, casos, acontecimentos), foram úteis ao garantir

\footnotetext{
${ }^{6} \mathrm{O}$ mesmo não pode ser dito para outras regiões de Moçambique tendo em vista diversos programas de alfabetização que, no início, ficam anos ensinando apenas o Português falado.
} 
para outros interessados nos estudos africanos, histórias que poderiam desaparecer em pouco tempo.

Assim, diante das complexas relações que se estabeleceram no emaranhado humano, que as memórias trouxeram, foi-nos possível contribuir, de alguma forma, para disseminar a riqueza histórica e sócio-cultural dos povos moçambicanos e, de forma específica, de habitantes nativos do país, moradores de Maputo, capital.

Deste modo, intentamos contribuir para com a afirmação da cidadania brasileira e moçambicana, uma vez que estas estão associadas à preservação da memória social das antigas colônias portuguesas, já que elementos oferecem subsídios ao cidadão e ao agente social sobre o conjunto de saberes, que vêm se acumulando, em decorrência de ações e estratégias produzidas historicamente.

Estes aspectos, delineados acima, nos faz retomar Desaulniers, para quem "a afirmação da cidadania associa-se à preservação da memória social" (1997, p. 3). E ainda:

[...] o empreendimento que se preocupa com a organização e a divulgação das informações que contêm a memória social, ao socializar/democratizar a história, cumpre com um dos fundamentos da produção científica e, ao mesmo tempo, com um dos pressupostos da cidadania" (DESAULNIERS, 1997, p. 3).

Entretanto, apesar dos esforços aqui delineados, algumas indagações permanecem ainda sem respostas, pois como observa Walter Benjamin,

[...] não se percebeu devidamente até agora que a relação ingênua entre o ouvinte e o narrador é dominada pelo interesse em conservar o que foi narrado. Para o ouvinte imparcial, o importante é assegurar a possibilidade da reprodução (BENJAMIN, 1993, p. 210).

A saber: por que muitos dos entrevistados não tinham histórias para contar, acerca do aprendizado da nossa língua? Será que não tinham mesmo, ou a língua usada na comunicação entrevistador-entrevistado foi inadequada? Na mesma direção, questionamos se a metodologia de pesquisa empre- 
gada foi adequada para nossos fins e, ainda, se o tempo do qual dispúnhamos foi suficiente, já que pesquisador e sujeitos tiveram pouco tempo para estabelecer laços de confiança que poderiam permitir maior exposição das trajetórias individuais. E ainda: até que ponto, enquanto pesquisadores, conseguimos o distanciamento necessário para a imparcialidade na condução das entrevistas?

Finalmente, compartilhamos com nosso leitor outras indagações: As relações familiares se conservam fundamentais na sociedade de Maputo, tal como nas típicas sociedades tradicionais africanas? Se isso for verdade, até que ponto a língua oficial conseguirá penetrar neste universo? Como? E, por último: a modelo do que ocorreu com quase a totalidade das nações colonizadas, a língua oficial passará, também, a ser a língua materna?

Diante do exposto, colocamo-nos a meta de dar continuidade a este trabalho de construção do conhecimento e convidamos os demais membros da comunidade acadêmica a partilharem conosco este caminho. Na verdade, pretendemos trilhar uma "nova rota do descobrimento" em busca deste saber, que nos foi negado, durante tantos anos, para além do período colonial no Brasil, na tentativa de contribuir para a efetiva implementação da Lei 11.645/08, por meio da organização e divulgação dos dados e resultados colhidos sobre as culturas africanas, pois acreditamos que ao compartilhálos, enriquecemos a memória social, tanto de brasileiros, como de moçambicanos, de angolanos, dentre outros povos.

\section{Referências bibliográficas}

BENJAMIN, Walter (1993). O narrador: Considerações sobre a obra de Nikolai Leskov. In: . Magia e Técnica, Arte e Política. Tradução de Sérgio Paulo Rouanet. São Paulo: Brasiliense.

BRASIL. Lei 11.645/08. Disponível em: 〈http://www.mec.gov.br>. Acesso em: 1 jun. 2008. 
CRAVEIRINHA, José. Craveirinha em poesia: seleção de poemas do autor. Disponível em: <www.fflch.usp.br/dlcv/posgraduacao/ecl/pdf/via05/via 05_09_1.pdf $>$. Acesso em: 21 maio 2006.

DESAULNIERS, Julieta Beatriz Ramos. Memória social e cidadania. Caderno CEDES, Campinas, ago. 1997, v. 18, n. 42, p. 93-107.

FERREIRA, Marieta de Moraes (Coord.) (1998). Entre-vistas: abordagens e usos da história oral. Rio de Janeiro: Editora da Fundação Getúlio Vargas.

MOÇAMBIQUE. Constituição. Disponível em: <http://www.mozambique. mz/pdf/constituicao.pdf>. Acesso em: 24 maio 2008.

MOUZINHO, Mário; NANDJA, Débora. A Alfabetização em Moçambique: desafios da educação para todos. In: EFA Global Monitoring 2006, UNESCO, Paris.

POLLAK, Michael. Memória e identidade social. In: Estudos Históricos, Rio de Janeiro, 1992, v. 5, n. 10, p. 200-212.

SECCO, Carmen Lucia Tindó Ribeiro. O mar, a ilha, a língua: a vertigem da criação na poesia de Virgílio de Lemos. Disponível em: <http://www.lus itanistasail.net/secco01.htm>. Acesso em: 21 maio 2008.

THOMPSON, Paulo (1992). A voz do passado: história oral. Rio de Janeiro: Paz e Terra.

TOURTIER-BONAZZI, C. Arquivos: propostas metodológicas. In: Usos \& Abusos da História Oral. Rio de Janeiro: Fundação Getulio Vargas, 2001, p. 233-46.

\section{AUTORAS}

\section{Nilce da SILVA}

Filiação institucional: FEUSP

E-mail: nilce@usp.br

\section{Aparecida do Carmo Frigeri BERCHIOR}

Filiação institucional: Faculdades Integradas Fafibe

E-mail: acfrigeri@zup.com.br 
Recebido em maio de 2008, aprovado em maio de 2008.

\section{Como citar este artigo:}

SILVA, Nilce da e BERCHIOR, Aparecida do Carmo Frigeri. Fragmentos da memória: cultura e língua portuguesa em Maputo, homenagem aos irmãos moçambicanos. Revista ACOALFAplp: Acolhendo a Alfabetização nos Países de Língua portuguesa, São Paulo, ano 3, n. 5, 2008. Disponível em: <http://www.acoalfaplp.net>. Publicado em: setembro 2008.

Sede da Edição: Faculdade de Educação da Universidade de São Paulo - Av da Universidade, 308 - Bloco A, sala 111 - São Paulo - SP - Brasil - CEP 05508-040. Grupo de pesquisa: Acolhendo Alunos em situação de exclusão social e escolar: o papel da instituição

$$
\text { escolar. }
$$

